\title{
Fungi and mycotoxins associated with egyptian sorghum grains
}

\begin{abstract}
The aim of the present work was to study the infected fungi and the mycotoxins contamination in Egyptian sorghum grains collected from different governorates. Forty eight sorghum grain samples were collected from six governorates (Cairo, Kaliobia, Gharbia, Alexandaria, Assute, and Sohage). Isolation and identification of fungi and the determination of mycotoxins (i.e. Aflatoxins Afs and Fumonisin $\mathrm{FB}_{1}$ ) were carried out. The results revealed that all samples were infected with at least one of fungi species. Nineteen fungi species belonging to five genera were isolated and identified from the investigated sorghum grain samples. Moreover, the result indicated that samples collected from Assute governorate were found to be more infected compared with the other governorates, meanwhile; samples collected from Kaliobia were found to be the lesser infected. All Aspergellus parasiticus and Fusarium moniliform isolated from sorghum grains were found to have the ability to produce $\mathrm{Afs}$ and $\mathrm{FB}_{1}$. In the same respect, results showed that aflatoxins were detected in $33.3 \%$ (16 out of 48 ) of the investigated samples with levels ranged from $0.17 \mu \mathrm{g} / \mathrm{kg}$ to $499 \mu \mathrm{g} / \mathrm{kg}$, while $\mathrm{FB}_{1}$ was detected in $16.6 \%$ ( 8 out of 48 ) of investigated samples with levels ranged from 7.2 to $129.5 \mu \mathrm{g} / \mathrm{kg}$. It is worthy to mention that the contamination levels of the investigated samples with aflatoxins were found below the Maximum Residue Limits (MRLs) established by International agencies or by the Egyptian standards.
\end{abstract}

Volume 3 Issue 3 - 2017

\author{
Osman MA,' Salama A,' Naguib KHM,'2 \\ Abdel-Wahhab MA, ${ }^{2}$ Sherif $\mathrm{SR}^{2}$ \\ 'Department of Food Science and Technology, Alazher \\ University, Egypt \\ 2Department of Food Toxicology and Contaminant, Egypt
}

Correspondence: Sherif Ramzy, Department of Food Toxicology and Contaminant, National Research Center, Dokki, Giza, Egypt, Email sheriframzy4@gmail.com

Received: June 18, 2017 | Published: June 27, 2017

\section{Introduction}

Mycotoxin contamination of agriculture commodities has become a natural phenomenon in many parts of the world. This may be due to favorable environmental condition prevalent in those regions coupled with the traditional method of crop cultivation, harvesting, handling and storage, all of which ultimately lead to severe mold growth and mycotoxin production in these agriculture commodities. The most frequently contaminated foods with mycotoxins producing molds include sorghum, corn, and wheat grains. ${ }^{1}$ The isolated fungi were found to have the ability to produce Aflatoxin $\mathrm{B}_{1} \mathrm{AFB}_{1}$ and $\mathrm{T}_{2}$ toxin. The risk of sorghum contamination by mycotoxins is related to mycoflora associated with the sorghum grain. The genus Fusarium was the most prevalent component of the internal seed borne mycoflora, genera Alternaria, phoma, penicillium and Aspergillus were also isolated whereas, the predominant Fusarium was Fusarium moniliforme and the most frequently isolated species of Alternaria, Phoma. Penicillium and Aspergillius were Alternaria, Penicillium sorghuma, Penicillium funiculosum and Aspergillus flavus, respectively. Diener et al., ${ }^{2}$ Gonzalez et al. ${ }^{3}$ Outbreaks of aflatoxicosis in farm animals have been reported from many areas of the world. The liver is mainly affected in such outbreaks and also in experimental studies on animals, including nonhuman primates. The acute liver lesions are characterized by necrosis of the hepatocytes and biliary proliferation, and chronic manifestations may include fibrosis. A feed level of aflatoxin as low as $300 \mu \mathrm{g} / \mathrm{kg}$ can induce chronic aflatoxicosis in pigs within 3-4 months Kusak et al. ${ }^{4}$ In animals, ingested aflatoxins may be metabolically degraded. Aflatoxin $B_{1}$ may be converted into aflatoxin $M_{1}$ which may occur in the milk. The concentration of aflatoxin $M_{1}$ in the milk of cows is about 300 times lower than the concentration of Aflatoxin $\mathrm{B}_{1}$ consumed in the feed. In certain experimental animals, only small amounts of administered aflatoxins have been found in tissues, $24 \mathrm{~h}$ after injection ${ }^{5,6}$ Aflatoxin $B_{1}$ is a liver carcinogen in at least 8 species including nonhuman primates. Dose-response relationships have been established in studies on rats and rainbow trout, with a $10 \%$ tumour incidence estimated to occur at feed levels of aflatoxin $\mathrm{B}_{1}$ of $1 \mu \mathrm{g} /$ $\mathrm{kg}$, and $0.1 \mu \mathrm{g} / \mathrm{kg}$, respectively. ${ }^{7}$ In some studies, carcinomas of the colon and kidney have been observed in rats treated with aflatoxins. ${ }^{8}$ Aflatoxin $\mathrm{B}_{1}$ causes chromosomal aberrations and DNA breakage in plant and animal cells and after microsomal activation, gene mutations in several bacterial test systems. ${ }^{9}$ In high doses, it may be teratogenic. ${ }^{10}$ Fumonisin $\mathrm{B}_{1}$ has been detected in maize and maizebased products worldwide at $\mathrm{mg} / \mathrm{kg}$ levels, sometimes in combination with other mycotoxins. Concentrations at $\mathrm{mg} / \mathrm{kg}$ levels have also been reported in food for human consumption. ${ }^{11}$ Available correlation studies from the Transkei, South Africa, suggested a link between dietary fumonisin exposure and oesophageal cancer. ${ }^{12}$ It is worthy to report that sorghum grain is one of the most popular feed and food in Egypt, questions arise concerning the detection and the prevalence of Aflatoxins and Fumonisin B1 and toxigenic fungi in Egyptian sorghum grain. This study attempted to assess some crop situation with respect to Aflatoxin and Fumonisin $\mathrm{B}_{1}$ through detecting the residues of these toxins as well as the incidence of toxigenic and other fungi in Egyptian sorghum grain. However attention was focused on Fusarium moniliform and Aspergillis parasiticus being the most common fungi responsible of Fumonisin and Aflatoxin production. In addition the Toxigenicity of isolated Fusarium moniliform and Aspergillis parasiticus were studied.

\section{Materials and methods}

\section{Materials}

Sorghum grain samples: Total of 48 sorghum grain samples were collected from different Egyptian Governorates (i.e. Cairo, Kaluobia. Al-Gharbia, Alexandria, Assute and Sohag) One kilogram of each sample was stored in polyethylene bag for the isolation of fungi and determination of Aflatoxins and Fumonisin $B_{1}$. 
Standard: Fumonisin $\mathrm{B}_{1}\left(\mathrm{FB}_{1}\right)$ and Aflatoxins $\mathrm{B}_{1}\left(\mathrm{AFB}_{1}\right),\left(\mathrm{AFB}_{2}\right)$, $\left(\mathrm{AFG}_{1}\right)$ and $\left(\mathrm{AFG}_{2}\right)$ standards were purchased from Sigma Chemical Co. (St. Louis, Mo. U.S.A.).

Thin layer chromatography (TLC) plates: TLC aluminum sheets $(20 \mathrm{X} 20 \mathrm{~cm})$ with $0.2 \mathrm{~mm}$ thickness of silica gel G60, without fluorescent indicator were purchased from Merck Co, (Darmstadt, Germany).

Sep- pack cartridge $\mathbf{C} 18$ columns: Sep- pack cartridge $\mathrm{C} 18$ columns were purchased from Waters Company (Water Company USA).

Media used: Potato dextrose agar (PDA) was purchased from SigmaAldrich France.

\section{Methods}

Isolation and identification of fungi associated with Egyptian sorghum grain: Potato dextrose agar medium (PDA), according. ${ }^{13}$ Culture media of Potato Dextrose Agar (PDA) was dissolved in distilled water by bringing to boil and autoclaved for $15 \mathrm{~min}$ at $121^{\circ} \mathrm{C}$. each sorghum grain samples (25 grains) were immersed in $2.5 \%$ sodium hypochlorite solution. After 2 min the sodium hypochlorite solution was drained off and the sterilized grains washed twice with sterilized distilled water. Distilled water was drained off, and then the grains were dried. Disinfected grains of each sample were plated Petri dishes (five grains / dish), and incubated for 5 day at $25^{\circ} \mathrm{C}$ and reported as mold count per $\mathrm{ml}$ of product.

Identification of the isolated fungi: The purified strains maintained on PDA slants were identified according to Nelson et al. ${ }^{14}$

Production of Aflatoxin by isolated Aspergillus parasiticus strains: Corn grains were moistened to $18 \%$ and artificially infected with isolated Aspergillus parasiticus. The infected substrate was incubated at $25^{\circ} \mathrm{C}$ for 15 days as recommended by Stubblefied et al. ${ }^{15}$

Production of $\mathrm{FB}_{1}$ by isolated fusarium moniliforme strains: One hundred gram of corn grains were transferred into Erlenmeyer flask, $29 \mathrm{ml}$ distilled water were added to the flask to adjust the moisture content to $43 \%$ and autoclaved at $121^{\circ} \mathrm{C}$ for $15 \mathrm{~min}$. The autoclaved corn grains were then inoculated with $1 \mathrm{ml}$ of spore suspension of the tested Fusarium moniliforme isolates and incubated in the dark for 28 days at $25^{\circ} \mathrm{C}$ (flasks were shaked daily during the first incubating week). After incubation period, corn grains cultures were dried over night at $50^{\circ} \mathrm{C}$ and finally ground with a blender and stored at $4{ }^{\circ} \mathrm{C}$ for analysis. ${ }^{16}$

\section{Detection and determination of aflatoxins in sorghum grain samples}

Preparation of working solution of aflatoxins: Diluted portions of stock solution to spotting concentration $(0.5 \mu \mathrm{g} / \mathrm{ml})$ using the same solvent used to prepare Aflatoxins standards. Standard solutions of Aflatoxins $B_{1}, B_{2}, G_{1}$ and $G_{2}$ were stable for more than one year.

\section{Extraction method}

Fifty grams of blended sorghum grains powdered representative sample was taken in a $1 \mathrm{~L}$ conical flask. Twenty five $\mathrm{ml}$ water, $25 \mathrm{gm}$ diatomaceous earth (celite) and $250 \mathrm{ml}$ chloroform were added. The flask was shaked for $30 \mathrm{~min}$ to extract the toxin. The content of the flask was filtered through filter paper. The first $50 \mathrm{ml}$ of filtrate were collected.

\section{Clean-up procedures}

Preparation of column chromatography: A ball of glass wool loosely placed in bottom of $22 \times 300 \mathrm{~mm}$ chromatographic column and $5 \mathrm{gm}$ of sodium sulphate anhydrous was added to give base for silica gel. The glass column was filled by $40-50 \mathrm{ml}$ of chloroform and $10 \mathrm{~g}$ of activated silica gel was added to the column. Finally $15 \mathrm{~g}$ of sodium sulphate anhydrous was added to be the top surface of the column. Then, $50 \mathrm{ml}$ of the sample extract was applied to the column. One hundred fifty $\mathrm{ml}$ of $\mathrm{n}$ hexane was used for de-fating followed by $150 \mathrm{ml}$ diethyl ether for de-pigmentation at a flow rate of $5 \mathrm{ml} / \mathrm{min}$. One hundred fifty $\mathrm{ml}$ of chloroform: methanol (97:3) was used to eluate the Aflatoxins from the column at a flow rate of $5 \mathrm{ml} / \mathrm{min}$. The elution was concentrated using a rotary evaporator to $1 \mathrm{ml}$ and directly transferred to a vial and dryness at $40^{\circ} \mathrm{C}$ to dry film.

Preliminary TLC: The vial containing dray extract residue was uncapped and 200ul benzene - acetonitrile $(98+2)$ was added and reseal with stopper. The vial containing extract was shaked vigorously to dissolve. The stopper was punctured to accommodate needle of 10ul syringe. In subdued incandescent light and as rapidly as possible $5 \mu \mathrm{l}$ was spotted on the imaginary line $3 \mathrm{~cm}$ from bottom of TLC plate. The vial was kept for quantitative analysis. On the same plate $5 \mu 1$ of Aflatoxin standards were spotted.

Fifty $\mathrm{ml}$ acetone: $\mathrm{CHCl} 3$ (1:9) were placed in the trough of the unlined developing tank. Only 1 plate per tank was used. Immediately the plate was into the tank and was sealed. The chamber was saturated with solvent before use. The plate was developed 40 minutes or until Aflatoxins reach top of the plat and then it was removed from the tank, the solvent was evaporated at room temperature and the plate was viewed under long wave UV lamp in a viewing chamber.

\section{Determination of aflatoxins by HPLC technique}

Derivatization: The derivatives of samples and standards were done as follow: Fifty $\mu 1$ trifluoracetic acid(TFA) were added to the dray film of standard and samples and the mixture was let to stand for $15 \mathrm{~min}$ followed by $450 \mu 1 \mathrm{H}_{2} \mathrm{O}: \mathrm{cH} 3 \mathrm{cN}(9: 1 \mathrm{v} / \mathrm{v})$ and they were mixed well by vortex for $30 \mathrm{~s}$ and the mixture was left to stand for $5 \mathrm{~min}$. In this step of reconstitution of the dry film, $\mathrm{AFB}_{1}$ and $\mathrm{AFG}_{1}$ were converted into other derivatives, $\mathrm{AFB}_{2}$ a and $\mathrm{AFG}_{2}$ a, respectively (Aflatoxins $\mathrm{G}_{1}$ and $\mathrm{B}_{1}$ have low florescence properties, therefore, they were converted to Aflatoxin $\mathrm{G}_{2} \mathrm{a}$ and $\mathrm{B}_{2} \mathrm{a}$, which have high fluorescence properties, using trifluoracetic acid). ${ }^{17}$

HPLC conditions: The HPLC instrument used for Aflatoxins determination was waters (474) system, equipped with quaternary pump fluorescence detector set system at $360 \mathrm{~nm}$ excitation and $440 \mathrm{~nm}$ emission wavelengths. The chromatography column was phenomenex C18. The mobile phase system $\left(\mathrm{H}_{2} \mathrm{O}: \mathrm{CH}_{3} \mathrm{OH}: \mathrm{CH}_{3} \mathrm{CN}, 30: 60: 10 \mathrm{v} / \mathrm{v} / \mathrm{v}\right)$ was isocratically at a flow rate of $1 \mathrm{ml} / \mathrm{min}$. Data were collected and integrated using (Totalchrom Navigator) Chromatography Manager Software.

\section{Detection and determination of FB I in sorghum grain samples}

Stock standard of $\mathbf{F B}_{1}$ : One $\mathrm{mg}$ of $\mathrm{FB}_{1}$ standards was dissolved in $1 \mathrm{ml}$ of Acetonitrile ACN: $\mathrm{H}_{2} \mathrm{O}(1: 1, \mathrm{v} / \mathrm{v})$.

Working standard solution: The working standard solution was prepared from stock standard solution by transferring $100 \mu 1,50 \mu 1$, $25 \mu 1$, and $10 \mu 1$ to 4 vial then $900 \mu 1,950 \mu 1,975 \mu 1$, and $990 \mu 1$, of 
$\mathrm{ACN}: \mathrm{H}_{2} \mathrm{O}(1: 1, \mathrm{v} / \mathrm{v})$ were added respectively. The obtained standard solutions contained $100 \mu \mathrm{g} / \mathrm{ml}, 50 \mu \mathrm{g} / \mathrm{ml}, 25 \mu \mathrm{g} / \mathrm{ml}$, and $10 \mu \mathrm{g} / \mathrm{ml} \mathrm{FB}_{1}$, respectively.

Extraction and cleanup of $\mathbf{F B}_{1}$ : The extraction and cleanup of FB1 from sorghum grain samples was carried out according to. ${ }^{17}$ Fifty grams of finely ground sorghum sample were transferred into an Erlenmeyer flask with $100 \mathrm{ml} \mathrm{ACN}: \mathrm{H}_{2} \mathrm{O}(1: 1, \mathrm{v} / \mathrm{v})$. The flask was shaked for $30 \mathrm{~min}$ to extract the toxin. The content of the flask was filtered through filter paper. Two $\mathrm{ml}$ of the filtered extract was combined with $5 \mathrm{ml}$ aqueous $1 \% \mathrm{KCL}$ and applied to a preconditioned C18 Sep-Pak column. The column was washed with $5 \mathrm{ml} 1 \%$ aqueous $\mathrm{KCL}$ followed by $5 \mathrm{ml}$ acetonitrile. Applied extract on $\mathrm{C} 18$ was washed with $5 \mathrm{ml} \mathrm{KCL} 1 \%$, followed by $2 \mathrm{ml}$ aqueous AcN: KCL (1:9), and the eluants were discarded. Fumonisin $\mathrm{B}_{1}$ was eluted with $4 \mathrm{ml} \mathrm{AcN}$ : $\mathrm{H}_{2} \mathrm{O}$ (7:3) and evaporated to dryness.

\section{Derivatization and HPLC analysis}

Preparation of derivatization reagent: Forty $\mathrm{mg}$ of o-phtaldialdehide OPA were dissolved in $1 \mathrm{ml}$ methanol and diluted with $4 \mathrm{ml}$ disodium tetra borate $(0.1 \mathrm{M})$ then $50 \mu 12$-mercaptoethanol were added. The reagent solution was stored in aluminum foil covered vial and was stored for no more than 1 week at room temperature in dark.

Preparation of standard derivatives: Fifty $\mu 1$ of $\mathrm{FB}_{1}$ working standard solution were transferred to base of small vial, then mixed with $225 \mu \mathrm{l}$ OPA reagent and $10 \mu 1$ of reacted mixture were injected to HPLC within 1min (It was critical to adhere to reproducible time between addition of OPA reagent and injection into HPLC system). Fluorescence of OPA- Fumonisin beginning to decrease after $2 \mathrm{~min}$.

Preparation of sorghum extract derivatives: The purified dry film residue of sample extract was dissolved in $200 \mu 1$ methanol. Fifty $\mu 1$ of this extract were transferred to base of small vial, then $225 \mu$ l OPA reagent were added, mixed, and $10 \mu 1$ derivative was injected to HPLC within $1 \mathrm{~min}$ of adding OPA reagent.

Determination of FB $_{1}$ by HPLC: The method described by Shephard et al. ${ }^{18}$ was used for the determination of $\mathrm{FB}_{1}$ in samples by HPLC.

\section{Chromatography conditions}

Stationary phase: Column Hyper Clone $5 \mu$ ODS (C18) 120A , DIM: 250x4.60mm. (Phenomenex).

Mobile phase: Methanol: $0.1 \mathrm{M} \mathrm{NaH} 2 \mathrm{PO} 4(75: 25, \mathrm{v} / \mathrm{v})$ isocratic system adjusted to $\mathrm{pH} 3.35$ by the addition of phosphoric acid and was filtered through membrane filter and it was pumped at $1 \mathrm{ml} / \mathrm{min}$ flow rate.

Detector: Fluorescence detector (Excision $335 \mathrm{~nm}$ and Emission $450 \mathrm{~nm})$.

\section{Quantitation}

The mixed solutions of standard as well as sample extract after derivatization were filtered through a $0.22 \mu \mathrm{m}$ membrane filter and loaded $(50 \mu \mathrm{l})$ into a $200 \mu \mathrm{l}$ injection loop. $\mathrm{FB}_{1}$ contents in sample were calculated from chromatographic peak areas using the standard curve.

\section{Statistical analysis}

All data were statistically analyzed using the General Linear Models Procedure of the Statistical Analysis System. ${ }^{19}$ The significance of the differences among results was determined by Waller-Duncan k-ratio. ${ }^{20}$ All statements of significance were based on probability of $\mathrm{P}<0.05$.

\section{Results and discussion}

\section{The total fungal counts and percentages of fungal infection in sorghum grain samples}

The occurrence and infection fungi of sorghum grains collected from different governorates (Cairo, Kaluobia, Gharbia, Alaxandaria, Assute and Sohage) were carried out. The results presented in (Tables $1 \& 2$ ) indicated the total fungal counts and percentage infection of sorghum grain samples. The total fungal count isolated from the sorghum grains collected from the aforementioned governorates were 313 isolates. Nineteen species belonging to five genera were isolated and identified from 48 samples of sorghum grains. Aspergillus, Alternaria, and Fusarium genera were the most frequently and were abundance greater than the other genera of fungi. The present results indicated that sorghum samples collected from Assute governorate were the most infected with molds since the percentage of infection was $19.8 \%$, followed by Alexandaria $18.5 \%$, this may be due to the increase of moisture content and or bad storage in these governorates, while, the infection of Cairo, Sohage, Gharbia and Kaliobia governorates were 16.9, 15.9, 14.3, 14.3\% respectively. Data presented in (Table 2) percentage of isolated fungi species which occurred in sorghum grain samples collected from different governorates and the results indicated that among the detected fungi, Aspergillus group was the most prevalent fungi in all examined samples. Within these speacies, Aspergillus Niger was the predominant and comprised $54.3 \%$ of the total fungal count of the isolates, followed by Aspergillus flavus, which was comprised $14.6 \%$, Alternaria was comprised $14.6 \%$. Whereas, Fusarium spp and Aspergellus parasiticus represented $4.7 \%$ and 4.1 respectively. The other species included Penicillium, Aspergillus ochrecus, Helminthosporium sativum, Aspergillus terreus, Aspergellus chevalier, Aspergellus humicola, Nigrospora sphaerica and Cephalosporium acremonium represented 2.5\%, $1.2 \%, 1.2 \%, 0.36 \%, 0.36 \%, 0.31 \%, 0.31 \%$ of the total fungal count respectively. These data revealed that the percentage infection of sorghum grains with fungi was high. This may be probably attributed mainly to the bad storage condition. These results were coincided with those reported by many investigators Diener et al., ${ }^{2}$ Gonzaleze et al., ${ }^{3}$ Bhat et al. ${ }^{21}$

Table I \%Number of isolated fungi spices from sorghum grains collected from different governorates

\section{Governorates Fungi isolate \% of TFC of each governorate}

$\begin{array}{lcc}\text { Cairo } & 53 & 16.9 \\ \text { Kaliobia } & 45 & 14.3 \\ \text { Gharbia } & 45 & 14.3 \\ \text { Alexandaria } & 58 & 18.5 \\ \text { Assute } & 62 & 19.8 \\ \text { Sohage } & 50 & 15.9\end{array}$


Table 2 Isolated fungal species and percentage of occurrence in sorghum grains collected from different governorates

\begin{tabular}{lll}
\hline Type of fungi & $\begin{array}{l}\text { No. of isolate } \\
\text { fungi }\end{array}$ & \% of infection \\
\hline Aspergillus Niger & 170 & 54.3 \\
Aspergillus flavus & 46 & 14.6 \\
Alternaria spp & 46 & 14.6 \\
Fusarium moniliform & 3 & 4.6 \\
Fusarium semiteetum & 2 & 0.95 \\
Fusarium graminearum & 2 & 0.63 \\
Fusarium equseti & 2 & 0.63 \\
Fusarium solani & 2 & 0.63 \\
Fusarium avenaceum & 2 & 0.63 \\
Penicillium sp & 8 & 2.55 \\
Aspergillus parasiticus & 15 & 4.1 \\
Aspergillus ocracues & 4 & 1.2 \\
Helminthosporium Sativium & 4 & 1.2 \\
Aspergillus terreus & 2 & 0.63 \\
Aspergillus chevalier & 2 & 0.63 \\
Aspergillus humicola & 1 & 0.31 \\
Nigrospora sphaerica & 1 & 0.31 \\
Sephalosporium acremonium & I & \\
\hline
\end{tabular}

Toxin production by some toxigenic fungi isolated from sorghum grains collected from different governorates

The ability of the isolated fungi to produce mycotoxins was examined in the current study. The results presented in (Table 3) indicated that Aspergillus parasiticus isolated from sorghum grain samples collected from Cairo has the ability to produce aflatoxin in a concentration ranged from 0.03 to $0.80 \mu \mathrm{g} / \mathrm{kg}$ sorghum grains. Whereas other strain was found to produce aflatoxins in concentrations reached $0.02,0.26,0.01$ and $2.98 \mu \mathrm{g} / \mathrm{kg}$ in the samples collected from Kaliobia, Gharbia, and Assute and Sohage governorates respectively. On the other hand, three species of Fusarium moniliform isolated from the samples collected from Kaliobia governorate was found to produce Fumonisin in a concentrations of $0.52,1.36$ and $1.05 \mu \mathrm{g} / \mathrm{kg}$ respectively.

\section{The natural occurrence of Aflatoxins in sorghum grain samples collected from different governorates}

Aflatoxins are secondary metabolites produced by certain strains of Aspergillus flavus and Aspergillus parasiticus. These fungi are ubiquitous and the potential for contamination of foodstuffs and animal feeds is widespread. The occurrence and magnitude of aflatoxin contamination varies with geographical and seasonal factors, and also with the conditions under which a crop is grown, harvest, and storage..$^{22}$ Crops in tropical and subtropical areas are more subject to contamination than those in temperate regions, since optimal conditions for toxin formation are prevalent in areas with high humidity and temperature. producing fungi can infect growing crops as a consequence of insect or other damage, and may produce toxins prior to harvest, or during harvesting and storage. ${ }^{23}$ The results of AFs concentration in the all samples collected from the six governorates (Cairo, Kaliobia, Gharbia, Alexandaria, Assute and Sohage) as determined by the HPLC are summarized in (Table 4). It is clear from these results that the AFs levels were ranged from (30 to 499), (0.17 to 13.6$),(0.34$ to 54.2$),(1.13$ to 17.1$)$ and $(0.64$ to 1.0$) \mu \mathrm{g} / \mathrm{kg}$ for Cairo, Kliobia, Gharbia, Alexandaria, Assute and Sohage. However, the presented data also revealed that AFs was detected in 33.3\% (16 out of 48) of the total samples analyzed with a total range from 0.17 to $499 \mu \mathrm{g} / \mathrm{kg}$. These results agreed with ${ }^{24}$ who reported that the sorghum grains are often damaged by the infected mold, such as Aspergillus and consequently aflatoxin contamination. The contamination with AFs in some collected sorghum grain samples can be probably attributed to the bad storage condition of sorghum grains in some regions of the examined governorates. In this regards, Ayalew et al., ${ }^{25}$ who reported that higher mycotoxin contamination in sorghum, may be related to the widespread storage of sorghum grain in the underground and the occurrence of pits may leading to elevated of seed moisture contents.

Table 3 Toxin production by some toxigenic fungi isolated from sorghum grain samples collected from different governorates

\begin{tabular}{llll}
\hline Fungi & Type of produced toxin by each fungi & Amount of fungal toxin ug/kg & Governorate \\
\hline Aspergillus parasiticus & $\mathrm{AFs}$ & 0.0332 & Cairo \\
Aspergillus parasiticus & $\mathrm{AFs}$ & 0.8023 & Cairo \\
Fusarium .moniliform & $\mathrm{FB}_{1}$ & 1.0519 & Kaliobia \\
Fusarium .moniliform & $\mathrm{FB}_{\mathrm{I}}$ & 0.526 & Kaliobia \\
Fusarium .moniliform & $\mathrm{FB}_{1}$ & 1.365 & Kaliobia \\
Aspergillus parasiticus & $\mathrm{AFs}$ & 0.022 & Kaliobia \\
Aspergillus parasiticus & $\mathrm{AFs}$ & 0.26 & Tanta \\
Aspergillus parasiticus & $\mathrm{AFs}$ & 0.0115 & Assute \\
Aspergillus parasiticus & $\mathrm{AFs}$ & 2.98 & Sohage \\
\hline
\end{tabular}

Occurrence of Fumonisin B I in sorghum grain samples collected from different governorates ( $\mathrm{ug} / \mathrm{kg}$ )

The results of $\mathrm{FB}_{1}$ residues which detected in all sorghum grain samples collected from the six selected governorates (Cairo, Kaliobia,
Gharbia, Alexandaria, Assute and Sohage) and analyzed by HPLC are summarized in (Table 5). It is clear from these results that the FB1 was found in concentration reached 39.3, 7.2, (23.9 to 37.3), (52.6 to 129.5 ), and $98.1 \mu \mathrm{g} / \mathrm{kg}$ for Cairo, Kaliobia, Gharbia, Alexandaria and Sohage governorate respectively. It is of interest to mention that 
sorghum samples collected from Assute governorate were found to be negative for FB1. The presented data revealed that FB1 was detected in $16.6 \%$ ( 8 out of 48 ) of the total samples analyzed with a total range from (7.2 to 129.5$) \mu \mathrm{g} / \mathrm{kg}$. These results may be attributed to the good transport and handling condition of sorghum grains and storage temperature. These results are also in agreement with those reported by Nair et al., ${ }^{26}$ who stated that Fumonisins are mycotoxins produced by Fusarium moniliforme that are prevalent in corn, sorghum, millet and other agricultural products. Silva et al., ${ }^{27}$ reported that the levels of Aflatoxin and Fumonisin contamination detected in the sorghum grains depended on the prevailing a biotic factors (moisture content, water activity, temperature, relative humidity, and mean rainfall) at the time of sampling. The effect of location and /or geographical distribution on the level of $\mathrm{FB}_{1}$ is shown in (Table 5). The level of $\mathrm{FB}_{1}$ was found to be in the range between (7.2 and 129.5) $\mu \mathrm{g} / \mathrm{kg}$ in Kaliobia and Alexandaria samples. Comparable results were performed in Assute, Kaliobia, Cairo and Sohage which reached (zero, 7.2, 39.3, and 98.1$) \mu \mathrm{g} / \mathrm{kg}$ but with a relatively lower percentage of incidence being (zero, $12.5 \%$ and $12.5 \%$ ) respectively.
Table 4 Natural occurrence of Aflatoxins in sorghum grain samples collected from different governorates $(\mu \mathrm{g} / \mathrm{kg})$

\begin{tabular}{lllllll}
\hline \multirow{2}{*}{ Replicates } & \multicolumn{6}{l}{ Governorates } \\
\cline { 2 - 7 } & Cairo & Kaliobia & Gharbia & Alex & Assute & Sohage \\
\hline I & ND & ND & ND & ND & 0.821 & ND \\
2 & ND & ND & ND & ND & 1.02 & ND \\
3 & ND & ND & ND & ND & ND & ND \\
4 & ND & ND & ND & ND & ND & ND \\
5 & 1703 & 0.174 & 54.25 & 17.16 & ND & ND \\
6 & 30.07 & 21.58 & ND & 1.59 & ND & ND \\
7 & 49910 & 2.811 & 0.3412 & ND & 0.6413 & ND \\
8 & ND & 13.614 & ND & 1.1315 & 0.8316 & ND \\
Mean \pm & 233 & 13.73 & 27.27 & 6.58 & 0.82 & \\
SE & \pm 139 & \pm 3.98 & \pm 26.93 & \pm 5.26 & \pm 0.07 & \\
\hline
\end{tabular}

Table 5 Natural occurrence of Fumonisin $B_{1}$ in sorghum grain samples collected from different governorates $(\mu \mathrm{g} / \mathrm{kg})$

\begin{tabular}{lllllll}
\hline \multirow{2}{*}{ Replicates } & \multicolumn{2}{l}{ Governorates } & & & \\
\cline { 2 - 6 } & Cairo & Kaliobia & Gharbia & Alex. & Assute & Sohage \\
\hline 1 & ND & ND & ND & ND & ND & ND \\
2 & ND & ND & ND & ND & ND & ND \\
3 & ND & ND & ND & ND & ND & ND \\
4 & ND & ND & ND & ND & ND & ND \\
5 & ND & 7.2 & 23.9 & 52.6 & ND & ND \\
6 & ND & ND & ND & ND & ND & ND \\
7 & 39.32 & ND & 37.3 & 96.1 & ND & ND \\
8 & ND & ND & ND & 129.5 & ND & 98.1
\end{tabular}

\section{Conclusion and recommendations}

From the obtained results concluded that sorghum grains infected by several fungal spices and their mycotoxins produced by these toxigenic isolated fungi and therefore we recommended surveys of $\mathrm{AFs}$ and $\mathrm{FB}_{1}$ in sorghum grains which should be continued.

\section{Acknowledgements}

None.

\section{Conflict of interest}

The author declares no conflict of interest.

\section{References}

1. Soares LM, Rodriguez Amaya. Screening and quantitation of ochratoxin Ain corn, peanuts, beans, rice and cassava. Journal - Association of Official Analytical Chemists. 1985;68(6):1128-1130.

2. Diener U, Morgan J, Wagener R, et al. Toxigenicity of fungi from grain sorghum. Mycopathologia. 1981;75(1):23-26.

3. Gonzalez HH, Martinez EJ, Resnik SL. Fungi associated with sorghum grain from Argentina. Mycopathologia. 199;139(1):35-41.
4. Kusak V. International programme on chemical safety. Czech Republic: Institute of Experimental Medicine Czechoslovak Academy of Sciences Prague Czechoslovakia; 1977.

5. Scott. Methods for determination of Aflatoxin M1 in milk and milk products - a review of performance characteristics. Food Addit Contam. 1989;6(3):283-305.

6. Creppy EE. Update of survey, regulation and toxic effect of mycotoxins in Europe. Toxicol Lett. 2002;127(1-3):19-28.

7. Eaton DL, Ramsdell HS, Neal GE. Biotransformation of Aflatoxins. In: Eaton DL, editor. The Toxicology of Aflatoxins: Human Health, Veterinary and Agricultural Significance. USA: Academic Press Inc; 1994.

8. Larsson P, Tjalve H. Extrahepatic bioactivation of aflatoxin B1 in fetal, infant and adult rats. Chem Biol Interact. 1995;94(1):1-19.

9. Adamson RH, Correa P, Dalgard DW. Brief Communication: Occurrence of primary liver carcinoma in rhesus monkey fed aflatoxin. BJ Nath Cancer Inst. 1973;50(2):549-553.

10. Phillips Douglas J. Aflatoxins in Almonds USDA Science and Education Administration. Agricultural Reviews and Manuals. 1980.

11. Abbas NF, Abdel Wahhab MA, Nada SA, et al. Potential Protective effect of HSCAS and Bentonite against dietary aflatoxicosis in rats: with special reference to chromosomal aberrations. Nat Toxins. 1998;6(5):211-218. 
12. Toxins derived from Fusarium moniliforme: Fumonisins $\mathrm{B}_{1}$ and $\mathrm{B}_{2}$ and fusarin C. IARC Monogr Eval Carcinog Risks Hum. 1993;56:445-466.

13. Harrigan WF, Nargaret EM. Grain storage studies. The fungus flora of stored wheat Cereal Chem. 1966;29:450-462.

14. Nelson PE, Toussoun TA, Marasas WF. Fusarium Spexies: An illustrated manual for identification. UK: Press University Park; 1983.

15. Stubblefied RD, Shotwell OL, Hesseltine CW, et al. Production of Aflatoxin on wheat and oats: Measurement with a recording densitometer. Appl Microbiol. 1967;15(1):186-190.

16. Bacon CW, Nelson PE. Fumonisin production in corn by toxigenic strains of Fusarium moniliforme and Fusarium proliferatum. $J$ of Food Prot. 1994;57(6):514-521.

17. Official Methods of Analysis of AOAC International. 17th ed. Nature Toxins. USA: AOAC International; 2000.

18. Shephard GS. Chromatographic determination of the Fumonisin mycotoxins. J Chromatogr A. 1998;815(1):31-39.

19. SAS User's Guide: statistics. USA: SAS Institute Inc; 1982.

20. Waller RA, Duncan DB. A Bayeule for the symmetric multiple comparison problems. J Am Stat Assoc. 1969;64:1484-1503.
21. Bhat Ramesh V, Shetty H, Vasanthi S. Human and animal health significance of mycotoxins in sorghum with special reference to Fumonisins. India: National Institute of Nutrition; 1998.

22. Mycotoxins: Risks in Plant, Animal, and Human Systems. Council for Agricultural Science and Technology. Task Force Report Ames, USA; 2003. p. 1-217.

23. International programe on chemical safety. Switzerland: World Health Organization; 1979.

24. Ratnavathi CV, Sashidhar RB. Substrate suitability of different genotypes of sorghum in relation to Aspergillus infection and Aflatoxin production. J Agric Food Chem. 2003;51(11):3482-3492.

25. Ayalew A, Fehrmann H, Lepschy J, et al. Natural occurrence of mycotoxins in staple cereals from Ethiopia. Mycopathologia. 2006;162(1):57-63.

26. Nair MG. Fumonisins and human health. Ann Trop Paediatr. 1998;18 Suppl:S47-S52.

27. Silva JB, Pozz CR, Mallozzi MA, et al. Mycoflora and occurrence of Aflatoxin $\mathrm{B}_{1}$ and Fumonisin $\mathrm{B}_{1}$ during storage of Brazilian sorghum. $J$ Agric Food Chem. 2000;48(9):4352-4356. 